\title{
Action Potential Bursting in Subicular Pyramidal Neurons Is Driven by a Calcium Tail Current
}

\author{
Hae-yoon Jung, Nathan P. Staff, and Nelson Spruston \\ Department of Neurobiology and Physiology, Institute for Neuroscience, Northwestern University, Evanston, Illinois 60208
}

Subiculum is the primary output area of the hippocampus and serves as a key relay center in the process of memory formation and retrieval. A majority of subicular pyramidal neurons communicate via bursts of action potentials, a mode of signaling that may enhance the fidelity of information transfer and synaptic plasticity or contribute to epilepsy when unchecked. In the present study, we show that a $\mathrm{Ca}^{2+}$ tail current drives bursting in subicular pyramidal neurons. An action potential activates voltage-activated $\mathrm{Ca}^{2+}$ channels, which deactivate slowly enough during action potential repolarization to produce an afterdepolarization that triggers subsequent action potentials in the burst. The $\mathrm{Ca}^{2+}$ channels underlying bursting are located primarily near the soma, and the amplitude of $\mathrm{Ca}^{2+}$ tail currents correlates with the strength of bursting across cells. Multiple channel subtypes contribute to $\mathrm{Ca}^{2+}$ tail current, but the need for an action potential to produce the slow depolarization suggests a central role for high-voltage-activated $\mathrm{Ca}^{2+}$ channels in subicular neuron bursting.

Key words: $\mathrm{Ca}^{2+}$ currents; HVA channels; bursting mechanism; subiculum; hippocampus; patch clamp
Subiculum, located adjacent to CA1, is the major output area of the hippocampal formation and has been suggested to integrate, reinforce, and distribute mnemonic and spatial information from the hippocampus to many cortical and subcortical regions, including thalamus, hypothalamus, and nucleus accumbens (Van Hoesen, 1982; Naber and Witter, 1998; O’Mara et al., 2001). Lesion studies support a role for subiculum in memory processing (Jarrard, 1986), and a human functional magnetic resonance imaging study demonstrated maximal activation of subiculum during memory recall (Gabrieli et al., 1997). Subiculum is also a major affected area in Alzheimer's disease, consistent with the loss of declarative memory associated with this disorder (Hyman et al., 1984; Davies et al., 1988).

An important feature of subiculum is the abundance of bursting neurons, which fire clusters of action potentials at high frequency $(>200 \mathrm{~Hz}$ ) (Staff et al., 2000). Bursting has been suggested to ensure reliable synaptic transmission at central synapses that have a low probability of transmitter release in response to a single action potential (Miles and Wong, 1986; Lisman, 1997; Snider et al., 1998) and to promote activity-dependent synaptic plasticity through high-frequency backpropagation into dendrites (Paulsen and Sejnowski, 2000). Conversely, abnormal bursting is known to be involved in the initiation and amplification of epileptiform activity (Wong and Prince, 1979; Alger and Nicoll, 1980; Traub and Wong, 1982). Thus, the tendency of subicular pyramidal neurons to burst is likely to be critical for the memory processing that occurs in this area and may also affect the spread of epileptic discharges in the hippocampal-entorhinal circuit (Stewart and Wong, 1993).

\footnotetext{
Received Dec. 11, 2000; revised Feb. 9, 2001; accepted Feb. 20, 2001.

This work was supported by National Science Foundation Grant IBN-9876032 and a grant from the Sloan and Klingenstein Foundations (N.S.). We thank Indira Raman, John Lisman, and Donald Cooper for helpful discussion and comments on this manuscript.

Correspondence should be addressed to Nelson Spruston, Department of Neurobiology and Physiology, 2153 North Campus Drive, Evanston, IL 60208-3520. E-mail: spruston@northwestern.edu.

Copyright (C) 2001 Society for Neuroscience $\quad 0270-6474 / 01 / 213312-10 \$ 15.00 / 0$
}

In many bursting neurons, burst firing is attributed to lowthreshold electrogenesis. A subthreshold $\mathrm{Na}^{+}$current has been suggested to contribute to bursting in some neocortical and entorhinal cortex layer 2 stellate cells (Alonso and Llinas, 1989; Silva et al., 1991; Mantegazza et al., 1998; Brumberg et al., 2000), whereas a low-threshold $\mathrm{Ca}^{2+}$ conductance (mediated by T-type $\mathrm{Ca}^{2+}$ channels) together with mixed-cation conductance $\left(I_{\mathrm{h}}\right)$ are responsible for the bursting of thalamic relay and dorsal root ganglion neurons (Deschenes et al., 1982; Jahnsen and Llinas, 1984; White et al., 1989). In the hippocampus and neocortex, $\mathrm{Ca}^{2+}$ conductances associated with dendritic $\mathrm{Ca}^{2+}$ spikes and/or persistent $\mathrm{Na}^{+}$currents have been suggested to mediate bursting (Wong and Prince, 1978; Azouz et al., 1996; Jensen et al., 1996; Golding et al., 1999; Helmchen et al., 1999; Larkum et al., 1999; Williams and Stuart, 1999). However, the underlying mechanism of bursting has remained unclear for subicular pyramidal neurons, the most robustly bursting neurons in the hippocampus.

Despite the importance of subiculum and its bursting properties for memory and disease, only a few studies have investigated the ionic basis of bursting in subicular neurons. Some authors have suggested that a $\mathrm{Ca}^{2+}$ conductance is crucial (Stewart and Wong, 1993; Taube, 1993), whereas others have argued that an $\mathrm{Na}^{+}$conductance is responsible for the depolarizing envelope that triggers burst firing in subicular neurons (Mattia et al., 1993, 1997). Here we report on an extensive series of experiments, using patch-clamp recordings and $\mathrm{Ca}^{2+}$ imaging in hippocampal slices, to determine the ionic mechanism of intrinsic bursting in subicular neurons.

\section{MATERIALS AND METHODS}

\section{Slice preparation}

Transverse hippocampal slices, with subiculum and entorhinal cortex attached, were prepared from 14- to 48-d-old Wistar rats. Animals were anesthetized with halothane and decapitated, and the brain was removed with the head immersed in ice-cold, artificial CSF (ACSF). Thirty-fiveto 48-d-old rats were perfused through the heart with ice-cold ACSF before decapitation, while under halothane anesthesia. The brain was mounted at a $60^{\circ}$ angle to the horizontal plane, and slices $(300 \mu \mathrm{m})$ were 
prepared using a vibratome (Leica, Nussloch, Germany). Slices were incubated for 20-40 min in an incubation chamber containing warm $\left(34-35^{\circ} \mathrm{C}\right) \mathrm{ACSF}$ and then held at room temperature. For recording, slices were transferred individually to a chamber on a fixed stage of a Zeiss (Oberkochen, Germany) Axioscop equipped with infrared differential interference microscopy. Recordings were obtained under visual control with infrared transmitted light and a Dage-MTI (Michigan City, IN) tube camera. All experiments were performed during continuous perfusion with ACSF at $33-36^{\circ} \mathrm{C}$.

\section{Solutions and drugs}

ACSF consisted of (in mM): $125 \mathrm{NaCl}, 25$ glucose, $25 \mathrm{NaHCO}_{3}, 2.5 \mathrm{KCl}$, $1.25 \mathrm{NaH}_{2} \mathrm{PO}_{4}, 2 \mathrm{CaCl}_{2}$, and $1 \mathrm{MgCl}_{2}, \mathrm{pH} 7.4$ (bubbled with $95 \% \mathrm{O}_{2}$ and $5 \% \mathrm{CO}_{2}$ ). Internal solution compositions are described in Patch-clamp recordings below. For most experiments, drugs (unless otherwise noted, Sigma, St. Louis, MO) were dissolved in ACSF and applied to the bath without interruption of flow. Control traces were collected for at least 1 min before drug applications, and the effect of drug were monitored thereafter. Once a drug effect was observed (3-15 min), the drug solution was washed out with normal ACSF to test for reversibility. Most drugs were fully reversible in the current-clamp condition, except $\mathrm{Cd}^{2+}$, zero $\mathrm{Ca}^{2+}$, and rCharybdotoxin (Alomone Labs, Jerusalem, Israel). In voltage-clamp experiments with nucleated patches, many patches did not last long enough to assess the reversibility, although we could partially wash out $\omega$-conotoxin MVIIC and 50-100 $\mu \mathrm{M} \mathrm{Ni}^{2+}$ (for rundown control in nucleated patches, see Voltage-clamp recordings below). In the experiments using $\mathrm{CdCl}_{2}$, phosphate was omitted in ACSF to prevent the precipitation of cadmium. For nimodipine, $10 \mathrm{~mm}$ stock solution was made with methanol in a dark container and diluted with ACSF to the final concentration before use. Nimodipine application was performed in dim-light conditions. In experiments using $1 \mathrm{mM} \mathrm{NiCl}_{2}$, it was either added to ACSF or substituted for $\mathrm{MgCl}_{2}$, but no difference in blocking effect on bursting was observed. For zero- $\mathrm{Ca}^{2+}$ and reduced $\mathrm{Ca}^{2+}$ solutions, $\mathrm{MgCl}_{2}$ was substituted for $\mathrm{CaCl}_{2}$. For local application experiments, puffer pipettes were made from patch electrodes broken to obtain a tip diameter of $10-20 \mu \mathrm{m}$ and filled with $5 \mathrm{mM} \mathrm{NiCl}_{2}$ (dissolved in ACSF) or normal ACSF. Fast green $(0.1 \%)$ was included in puffer pipette solutions. Application of gentle pressure produced a green band of $\sim 20 \mu \mathrm{m}$ in diameter, which was directed at either the soma or apical dendrite.

\section{Patch-clamp recordings}

Current-clamp recordings. Whole-cell, current-clamp recordings were made from either the soma or simultaneously from the soma and a dendrite. BVC-700 amplifiers (Dagan, Minneapolis, MN) were used for most current-clamp recordings (but see Voltage-clamp recordings). Patch-clamp electrodes were fabricated from thick-walled borosilicate glass and fire polished to resistances of 3-8 $\mathrm{M} \Omega$ in the bath. The intracellular solution for whole-cell current-clamp recordings contained (in $\mathrm{mM}$ ): $115 \mathrm{~K}$-gluconate, $20 \mathrm{KCl}, 10 \mathrm{Na}_{2}$-phosphocreatine, $10 \mathrm{HEPES}$, 2 EGTA, $2 \mathrm{Mg}$-ATP, and $0.3 \mathrm{Na}-\mathrm{GTP}, \mathrm{pH} \mathrm{7.3}$, and in some cases $0.1 \%$ biocytin for subsequent morphological identification.

Data were stored on a Power Macintosh computer (Apple Computers, Cupertino, CA) via an ITC-16 interface (Instrutech, Port Washington, NY). Data acquisition was performed using Pulse Control software (R. Bookman, University of Miami, Miami, FL) running under Igor Pro (WaveMetrics, Lake Oswego, OR). Voltage was filtered at $5 \mathrm{kHz}$ and digitized at $20 \mathrm{kHz}$.

Voltage-clamp recordings. All voltage-clamp recordings were obtained in the nucleated-patch configuration using an EPC-7 amplifier (Heka Elektronik, Lambrecht/Pfalz, Germany). Electrodes (3-5 M $\Omega$ ) were pulled and fire polished as described above. To reduce capacitance,
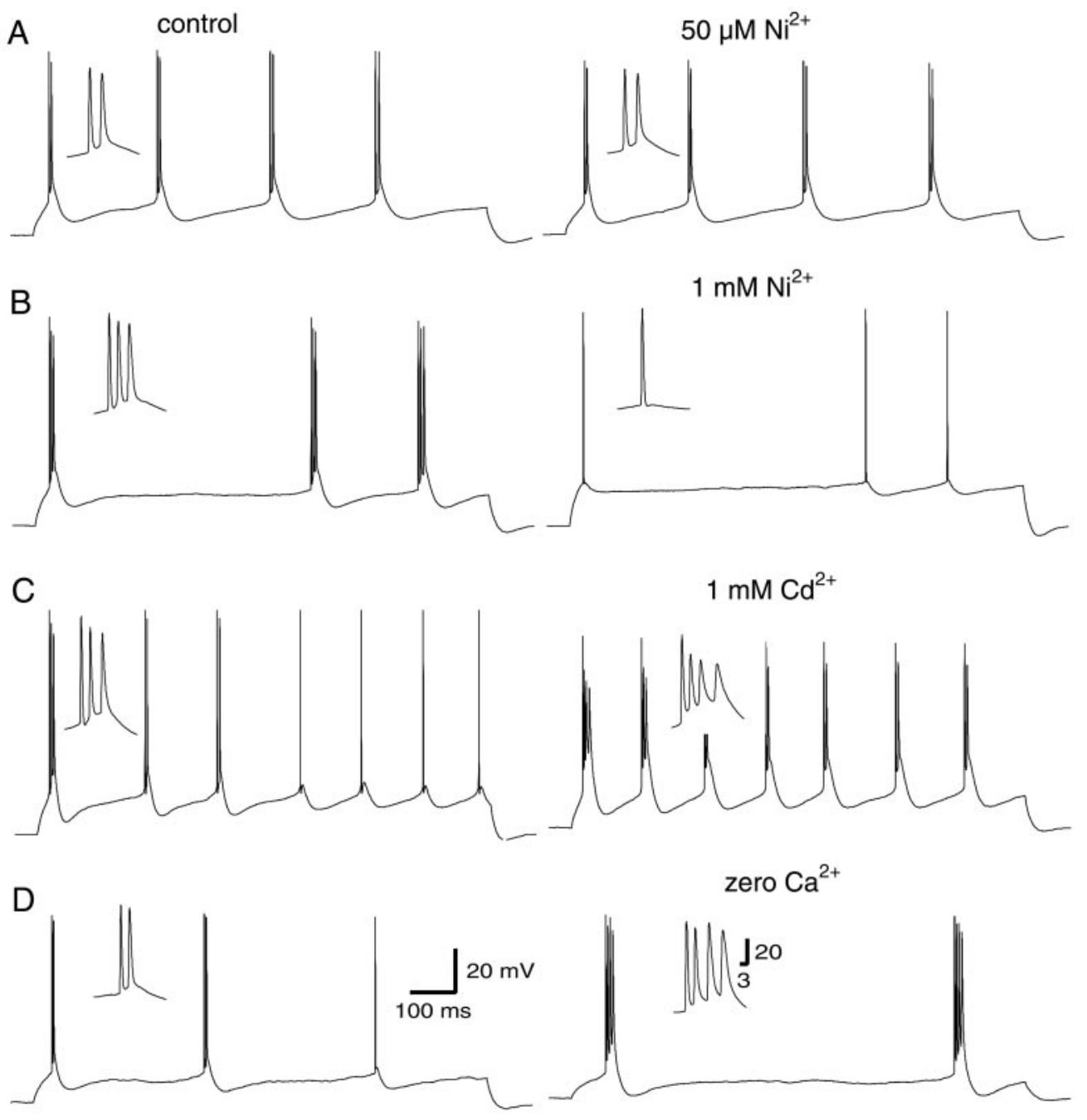

Figure 1. Effects of $\mathrm{Ca}^{2+}$ channel blockers on bursting. The left column shows the firing pattern in response to 1 sec current injections in the control condition. The right column shows the firing of the same neurons in response to a comparable current injection after the bath application of $50 \mu \mathrm{M} \mathrm{Ni}^{2+}(A)$, $1 \mathrm{mM} \mathrm{Ni}^{2+}(B), 1 \mathrm{mM} \mathrm{Cd}^{2+}(C)$, and zero $\mathrm{Ca}^{2+}$ solution $(D)$. Insets show the first burst of each trace on an expanded time scale. Note that $1 \mathrm{mM} \mathrm{Ni}^{2+}$ application blocks the strong bursting completely, whereas other manipulations have no effect or increase the bursting. Calibration bars in $D$ apply to all panels. The third burst on the right panel in $C$ is truncated to accommodate the inset. The range of currents injected was 70-310 pA. 
electrodes were wrapped with Parafilm, and the remaining patch-pipette capacitance was compensated. Nucleated patches were obtained by forming the whole-cell configuration on somata near the surface of the slice and then withdrawing the pipette, with negative pressure $(0.5-1.5 \mathrm{psi})$ in the pipette, until seal reformation occurred with the nucleus inside a large, outside-out patch. For the mixed $\left(\mathrm{Na}^{+}, \mathrm{Ca}^{2+}\right.$, and $\left.\mathrm{K}^{+}\right)$current recordings, K-gluconate-based internal solution (the same as in currentclamp recordings) was used, and the firing pattern of each cell was identified in the current-clamp mode (EPC-7 amplifier) before obtaining nucleated patches. For other current recordings, intracellular solutions were either $\mathrm{CsCl}$ based (in mM:130 CsCl, $10 \mathrm{Na}_{2}$-phosphocreatine, 10 HEPES, 2 EGTA, $2 \mathrm{MgATP}$, and $0.3 \mathrm{Na}_{2} \mathrm{GTP}, \mathrm{pH}$ 7.3) or Cs-gluconate based (115 mM Cs-gluconate plus $20 \mathrm{~mm} \mathrm{CsCl}$ was substituted for 130 $\mathrm{mm} \mathrm{CsCl}, \mathrm{pH} 7.3)$ as indicated in Results. The identification of bursting pattern was performed separately as described in Current-clamp recordings. In experiments for pharmacology and reversal potential, action potential firing patterns were not characterized; instead, cells with relatively large $\mathrm{Ca}^{2+}$ tail currents (maximum tail peak of $>80 \mathrm{pA}$ ) were considered. In pharmacological experiments, to correct for rundown of current during each experiment, a linear fit to the data before drug application was used to estimate baseline current. Membrane potentials reported are not corrected for a $-8 \mathrm{mV}$ liquid junction potential present when using gluconate-based internal solutions.

Recorded current was filtered at $3 \mathrm{kHz}$ and sampled at $50 \mathrm{kHz}$. Data analysis was performed with IGOR pro software. Currents were acquired using a $\mathrm{P} / 6$ to $\mathrm{P} / 9$ protocol (depending on the command potentials) to subtract leak and capacitive currents. Analysis was performed using averages of $2-10$ responses. Values are reported as mean \pm SEM.

\section{Calcium imaging}

Calcium imaging experiments were performed using K-gluconate-filled patch pipettes, substituting $0.15 \mathrm{~mm}$ fura- 2 for EGTA. Optical signals were monitored using a cooled, back-illuminated, frame-transfer CCD camera (512BFT; Princeton Instruments, Trenton, NJ). Fluorescence excitation was at $380 \mathrm{~nm}$ and emission was at $510 \mathrm{~nm}$. Imaging was performed at $20 \mathrm{~Hz}$ and was synchronized with the electrophysiology data via trigger pulses to the camera controller. Fluorescence intensity was binned on the chip in defined regions of interest in the soma or proximal apical dendrite. For each trial, a record of $\mathrm{d} F / F$ was calculated, where $\mathrm{d} F$ is the change in fluorescence induced by a stimulus, and $F$ is the absolute fluorescence just before delivery of the current stimulus. All fluorescence values are corrected for slice autofluorescence by performing background subtraction using a region of interest adjacent to the cell. Bleaching was not detected under our experimental conditions.

\section{RESULTS}

We first tested the involvement of T-type $\mathrm{Ca}^{2+}$ channels in subicular bursting using a low concentration of $\mathrm{Ni}^{2+}$, which blocks some T-type $\mathrm{Ca}^{2+}$ channels (Fox et al., 1987; Lee et al., $1999 \mathrm{~b})$. Bath application of $50-500 \mu \mathrm{M} \mathrm{Ni}^{2+}$ did not block bursting $(n=7)$ (Fig. $1 A)$, although burst firing was slightly increased or decreased depending on the application time and/or concentration. However, bursting was completely blocked by increasing the $\mathrm{Ni}^{2+}$ concentration to $1 \mathrm{mM}(n=22)$ (Fig. $\left.1 B\right)$, suggesting that high- $\mathrm{Ni}^{2+}$-sensitive $\mathrm{Ca}^{2+}$ channels may drive bursting. Other nonselective blockers of voltage-gated $\mathrm{Ca}^{2+}$ channels, however, such as $0.25-1 \mathrm{mM} \mathrm{Cd}^{2+}$ or a $\mathrm{Ca}^{2+}$-free solution, failed to block bursting during $1 \mathrm{sec}$ current injections but instead induced more robust bursting with a decrease in spike amplitude $(n=10$ and 11$)$ (Fig. 1C,D).

To reconcile these apparently contradictory results, we wanted to identify the ionic conductance blocked by a high concentration of $\mathrm{Ni}^{2+}$. Before that, however, we investigated where the bursts were generated, so the appropriate subcellular region could be studied in the subsequent voltage-clamp recordings. In 19 simultaneous whole-cell recordings from the soma and apical dendrite (51-140 $\mu \mathrm{m}$ from the soma) of subicular bursting neurons, we found that the somatic action potential always preceded the dendritic action potential within a burst (Fig. $2 A$ ), regardless of whether the current was injected through the somatic or dendritic

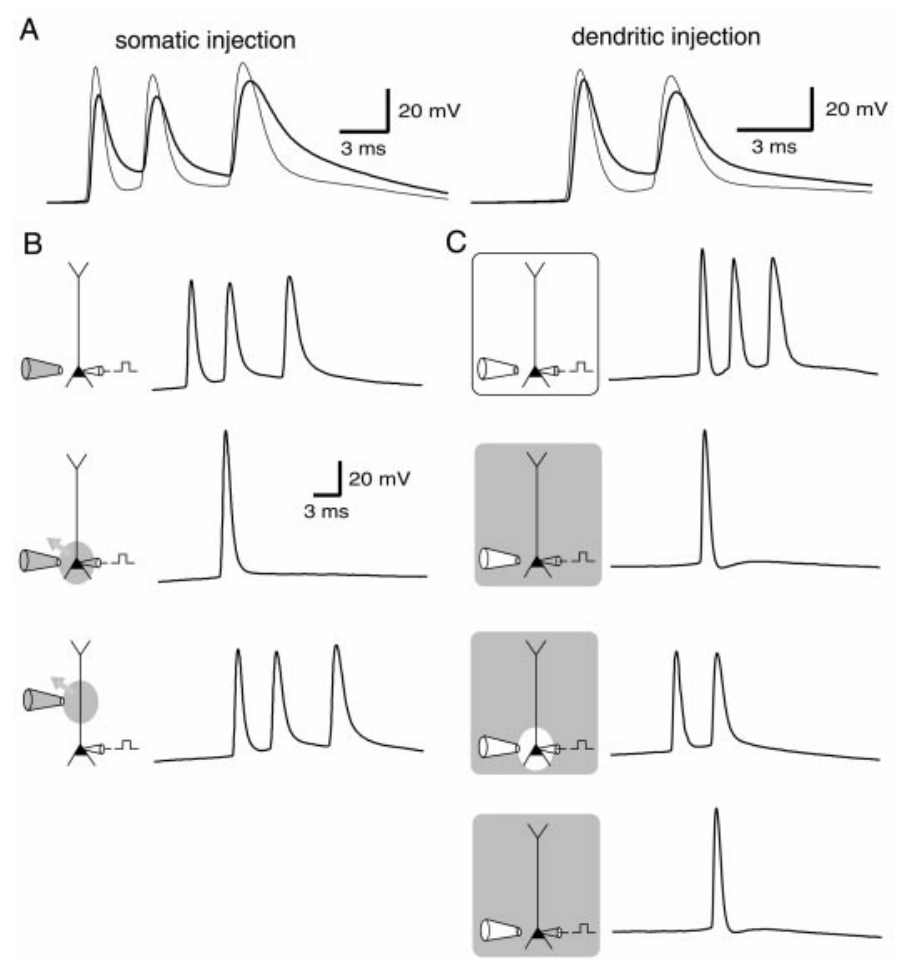

Figure 2. Axosomatic initiation of bursting in subicular pyramidal neurons. $A$, Simultaneous somatic and dendritic recordings show that somatic action potentials always precede dendritic action potentials, regardless of the location of current injection. Thin and thick traces are recordings from somatic and dendritic (104 $\mu \mathrm{m}$ from the center of the soma) recording pipettes, respectively. Left, Somatic current injection (110 pA). Right, Dendritic current injection (190 pA). Note that bursting has a higher current threshold and fewer spikes within a burst with dendritic injection. $B$, Local application of a high concentration of $\mathrm{Ni}^{2+}$ to the soma blocks the bursting. The application pipette contained $5 \mathrm{mM} \mathrm{Ni}^{2+}$ dissolved in ACSF (shading). Top, Control bursting. Middle, Local application of $5 \mathrm{~mm}$ $\mathrm{Ni}^{2+}$ to the somatic region blocked bursting. Bottom, Local application of $5 \mathrm{mM} \mathrm{Ni}^{2+}$ to the dendritic region did not affect bursting. $C$, Somatic application of normal ACSF in a $\mathrm{Ni}^{2+}$-containing bath solution $(1 \mathrm{mM}$ $\mathrm{NiCl}_{2}$; shading) restores bursting. Top, Control bursting. Second, $\mathrm{Ni}^{2+}$ (1 $\mathrm{mM})$ in the bath blocked the bursting. Third, Application of normal ACSF to the somatic area restored bursting. Bottom, Washout of normal ACSF stopped the bursting. The calibration bar in $B$ applies to all panels in $B$ and $C$.

electrode. The delay in action potential peak $\left(t_{\text {dend }}-t_{\text {soma }}\right)$ obtained from the most distal recordings (100-140 $\mu \mathrm{m}$ from the soma; $n=4$ ) was $260 \pm 4,300 \pm 4$, and $560 \pm 9 \mu \mathrm{sec}$ for the first, second, and third action potentials in a burst. Dendritic injection almost always required larger currents to reach action potential threshold, and sometimes there were fewer action potentials within a burst compared with somatic injection. These results show that, during bursting, action potentials are generated near the soma (probably in the axon) and propagate back into the dendrites (Stuart et al., 1997).

To determine the subcellular location of the $\mathrm{Ni}^{2+}$-sensitive conductance underlying bursting, we locally applied a high concentration of $\mathrm{Ni}^{2+}$, using pressure ejection from puffer pipette (see Materials and Methods). Somatic application of $\mathrm{Ni}^{2+}$ blocked bursting completely, whereas dendritic application did not block the bursting $(n=3)$ (Fig. $2 B$ ), implying a near-somatic location of $\mathrm{a} \mathrm{Ni}^{2+}$-sensitive conductance. To confirm this result, we applied $1 \mathrm{mM} \mathrm{Ni}^{2+}$ in the bath to block bursting and then locally applied normal solution to the somatic area to determine 
A

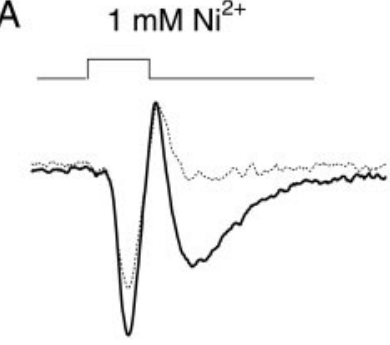

B zero $\mathrm{Ca}^{2+}$

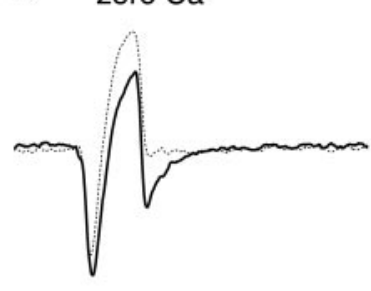

$\underline{\mathrm{C}}$

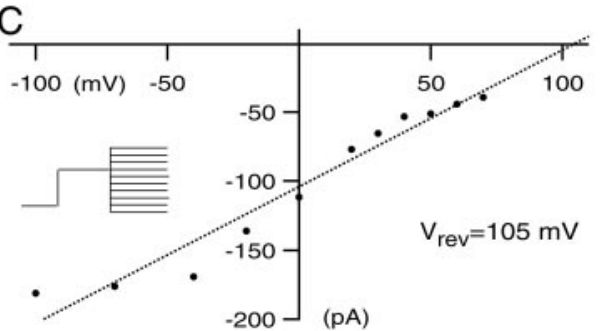

(pA)
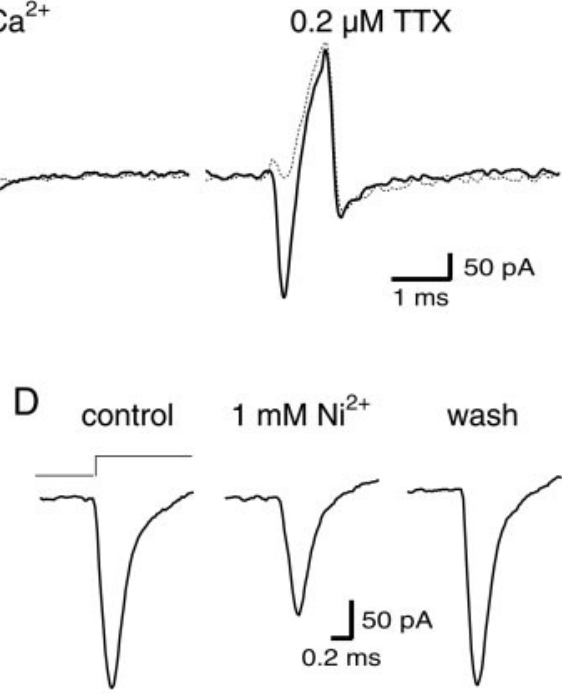

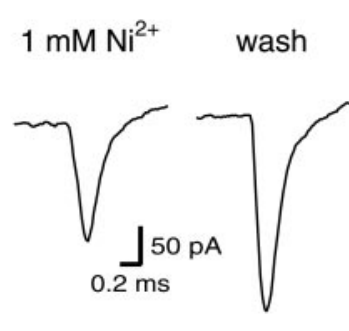

Figure 3. Voltage-activated currents in nucleated patches of subicular pyramidal neurons. $A$, $B$, Mixed currents $\left(\mathrm{Na}^{+}, \mathrm{Ca}^{2+}\right.$, and $\left.\mathrm{K}^{+}\right)$in response to $1 \mathrm{msec}$ step depolarizations from -70 to $0 \mathrm{mV}$ to mimic an action potential $(A, t o p)$. Currents shown were measured from strong bursting subicular neurons. Data were obtained with a K-gluconate-based internal solution. Solid and dashed traces are control and after drug application, respectively. Each trace is an average of two to four responses. $A$, Tail currents are almost completely blocked by $1 \mathrm{mM} \mathrm{Ni}^{2+}$. $B$, In a different patch, tail currents are also blocked by a zero $\mathrm{Ca}^{2+}$ solution but not by $0.2 \mu \mathrm{M}$ TTX. Note that inward tail currents are seen even when large outward currents dominated the response during the step. $C$, Reversal potential of an isolated tail current is extrapolated to +105 $\mathrm{mV}$ in a nucleated patch from a subicular neuron. Data were obtained with Cs-gluconatebased solution. Each point was measured from a tail current (average of 2 responses) obtained by repolarization to different potentials from a 1 msec step to $+20 \mathrm{mV}$ (inset). $D$, Effect of $\mathrm{Ni}^{2+}$ on isolated $\mathrm{Na}^{+}$currents. $\mathrm{Ni}^{2+}(1 \mathrm{mM})$ reversibly blocks the $\mathrm{Na}^{+}$currents $(48 \%$ blocked in this patch). Each trace is an average of five responses. Data were obtained with a CsCl-based internal solution.

whether bursting recovered. As shown in Figure $2 C$, we were able to restore bursting $(n=2)$ in this way. Together, these results show that the high- $\mathrm{Ni}^{2+}$-sensitive conductance mediating bursting is primarily located in the soma, proximal dendrites, or axon, although we cannot totally exclude the possibility of a dendritic contribution for enhancing bursting in subicular neurons. A relevant observation in this regard is that action potentials measured in the dendrites of subicular neurons repolarize less than their somatic counterparts (Fig. $2 A$ ). This effect, which could be attributable to a lower density of dendritic $\mathrm{K}^{+}$channels, could lead to additional current flow back to the soma to contribute to bursting.

Because the $\mathrm{Ni}^{2+}$-sensitive conductance was revealed to be located in the region including the soma, we decided to study these currents using nucleated-patch recordings, which provide large currents and good voltage control. Subicular pyramidal neurons show different firing patterns, which we classified as strong bursting, weak bursting, and regular spiking neurons, according to previously reported criteria (Staff et al., 2000). Therefore, we first performed current-clamp recordings using a K-gluconate-containing electrode to determine the firing pattern of each neuron, then excised a nucleated patch from the same neuron (with the same electrode), and measured mixed currents $\left(\mathrm{Na}^{+}, \mathrm{Ca}^{2+}\right.$, and $\left.\mathrm{K}^{+}\right)$in voltage-clamp recordings. Using brief depolarizing steps to mimic an action potential, a fast inward $\mathrm{Na}^{+}$current followed by an outward $\mathrm{K}^{+}$current was typically observed in all patches from subicular neurons. In most neurons, a large inward tail current after the offset of the depolarization was prominent. This inward tail current was often seen even in the presence of large outward currents during the depolarizing step (Fig. $3 A, B$ ). The inward tail current was eliminated by $1 \mathrm{~mm}$ $\mathrm{Ni}^{2+}(n=4)$ or a $\mathrm{Ca}^{2+}$-free solution $(n=10)$ but was not affected by $0.2 \mu \mathrm{M}$ TTX $(n=2)$. Contributions of $\mathrm{K}^{+}$currents to the tail were eliminated in another series of experiments using a Cs-gluconate-based internal solution. TTX $(0.5 \mu \mathrm{M})$ had almost no effect on the tail current $(97 \pm 1 \%$ of the control current remained; $n=5$ ). Under these conditions, the reversal potential of the tail current was linearly extrapolated to $+102 \pm 1 \mathrm{mV}(n=$ 4) (Fig. 3C). These results suggest that, in bursting neurons, a brief depolarization activates a high- $\mathrm{Ni}^{2+}$-sensitive $\mathrm{Ca}^{2+}$ con- ductance, which remains on long enough after repolarization to generate a substantial inward tail current.

We also noticed that $1 \mathrm{mM} \mathrm{Ni}^{2+}$ seemed to block a substantial fraction of fast, inward current (Fig. $3 A$ ). To better investigate whether this effect was mediated by a decrease in $\mathrm{Na}^{+}$current or an increase in $\mathrm{K}^{+}$current, we performed voltage-clamp recordings with $\mathrm{CsCl}$-containing electrodes, which isolate $\mathrm{Na}^{+}$currents (internal $\mathrm{Cs}^{+}$blocks $\mathrm{K}^{+}$currents, and $\mathrm{Ca}^{2+}$ currents were found to wash out rapidly with $\mathrm{Cl}^{-}$-based internal solutions). As shown in Figure $3 D$, almost half of the fast inward current was blocked by $1 \mathrm{mM} \mathrm{Ni}^{2+}(41 \pm 3 \% ; n=11)$, suggesting that at this concentration $\mathrm{Ni}^{2+}$ partially blocks the fast $\mathrm{Na}^{+}$currents.

To dissect the relative contributions of $\mathrm{Na}^{+}$and $\mathrm{Ca}^{2+}$ channel block to the efficacy of $\mathrm{Ni}^{2+}$ as a blocker of bursting, we examined the effects of a $\mathrm{Ca}^{2+}$-free solution and a low concentration of TTX (15 nM, which blocks a similar fraction of $\mathrm{Na}^{+}$channels as $1 \mathrm{mM} \mathrm{Ni}^{2+}$ ) on bursting elicited by short current pulses. Both of these conditions blocked bursting, but the way in which bursting was blocked differed. Using short depolarizing current injections, it was apparent that bursts were driven by a slow depolarization. This slow depolarization was triggered by the first action potential, because it was not present in responses just below threshold (Fig. 4A). Whereas zero $\mathrm{Ca}^{2+}$ blocked bursting by reducing this slow afterdepolarization $(n=4)$ (Fig. $4 A)$, low TTX did not reduce the afterdepolarization as much but blocked bursting by raising the threshold for action potential initiation $(n=3)$ (Fig. $4 B$ ). To better illustrate this disparity, we prevented bursting by injecting a hyperpolarizing current at the end of the brief depolarizing current pulse. In this condition, it was apparent that lowering $\mathrm{Ca}^{2+}$ reduced the afterdepolarization after the action potential, whereas low TTX did not. This difference in the effects of blocking $\mathrm{Na}^{+}$and $\mathrm{Ca}^{2+}$ channels was also apparent during sequential application of low TTX, followed by low TTX in zero $\mathrm{Ca}^{2+}(n=3)$ (Fig. $\left.4 C\right)$. Here it appears that low TTX had little effect on the afterdepolarization, whereas zero $\mathrm{Ca}^{2+}$ reduced it substantially $(n=4)$. The remaining afterdepolarization in zero $\mathrm{Ca}^{2+}$ (Fig. 4A,C) could be attributable to either incomplete block of $\mathrm{Ca}^{2+}$ current or a relatively passive terminal decay of the action potential caused by rapid deactivation of $\mathrm{K}^{+}$currents. 
A
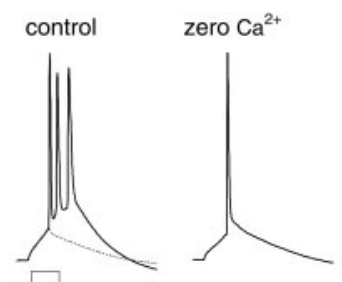

B

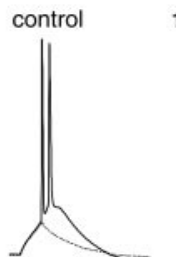

15 nM TTX
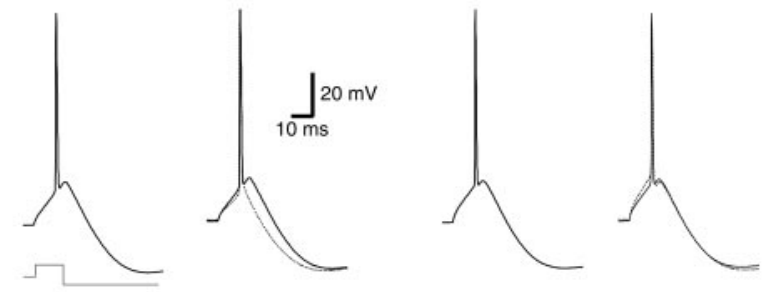

C
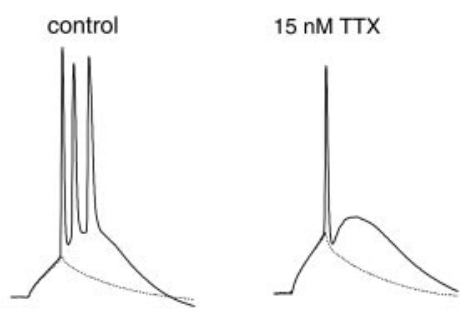

zero $\mathrm{Ca}^{2+}+15 \mathrm{nM}$ TTX

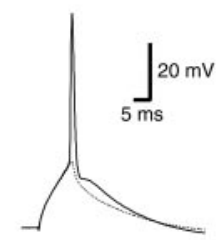

Figure 4. Bursting is driven by a $\mathrm{Ca}^{2+}$-dependent afterdepolarization. The effect of zero $\mathrm{Ca}^{2+}(A)$, low concentration of TTX $(B)$, or both $(C)$ on bursting induced by a short $(10 \mathrm{msec})$ current injection are shown. In the bottom panels of $A$ and $B$, hyperpolarizing current was given after the $10 \mathrm{msec}$ pulse to reveal an afterdepolarization without additional spikes (see diagram). $A$, Zero $\mathrm{Ca}^{2+}$ prevents bursting by reducing the afterdepolarization underlying the burst. Top, Responses in control $(+380 \mathrm{pA}$, dashed lines; $+390 \mathrm{pA}$, solid lines $)$ and zero $\mathrm{Ca}^{2+}(+250 \mathrm{pA})$. Bottom, Control $(+400 \mathrm{pA}$, solid lines $)$ and zero $\mathrm{Ca}^{2+}(+260 \mathrm{pA}$, dashed lines $)$ with $-350 \mathrm{pA}$ hyperpolarization after the pulse. $B$, TTX (15 nM) blocks bursting by raising threshold for action potential generation and not by affecting an afterdepolarization. Top, Responses in control $(+490 \mathrm{pA}$, solid lines; $+480 \mathrm{pA}$, dashed lines $)$ and $15 \mathrm{~nm}$ TTX $(+570 \mathrm{pA})$. Bottom, Control (+490 pA, solid lines) and $15 \mathrm{~nm}$ TTX (+560 pA, dashed lines) with $-450 \mathrm{pA}$ hyperpolarization after the pulse. $C$, Sequential application of a low concentration of TTX and zero $\mathrm{Ca}^{2+}$ confirm the ionic basis of the afterdepolarization underlying subicular bursting. Threshold and subthreshold responses are indicated by solid and dotted lines, respectively. Control responses $(+380$ and $390 \mathrm{pA})$ show that an afterdepolarization induced by the first spike (compared with the just subthreshold response) drives the second and third spikes after the end of the pulse. Application of $15 \mathrm{~nm}$ TTX $(+530$ and $540 \mathrm{pA})$ blocks the bursting by reducing the available $\mathrm{Na}^{+}$channels but has no obvious effect on the underlying afterdepolarization. Subsequent removal of $\mathrm{Ca}^{2+}(+590$ and $600 \mathrm{pA})$ eliminates most of the afterdepolarization.

Decay of the action potential may also be slowed in zero $\mathrm{Ca}^{2+}$ because of indirect block of $\mathrm{Ca}^{2+}$-activated $\mathrm{K}^{+}$currents. This slow decay of the action potential in zero $\mathrm{Ca}^{2+}$ may also contribute to the inability of zero $\mathrm{Ca}^{2+}$ and $\mathrm{Cd}^{2+}$ to block bursting during long current steps (Fig. 1), a point that we return to later.

Based on the above results, we hypothesized that tail currents mediated by voltage-gated $\mathrm{Ca}^{2+}$ currents drive an afterdepolarization that produces bursting in subicular neurons. To correlate bursting with $\mathrm{Ca}^{2+}$ tail currents, we measured tail currents from neurons with an identified action potential firing pattern. To do so, neurons were first patched with a K-gluconate-containing electrode, and the firing pattern was observed in the currentclamp mode. The electrode was then withdrawn to form a highresistance seal, and the same neurons were repatched with a
Cs-gluconate-containing electrode to obtain nucleated patches for current recordings with $\mathrm{K}^{+}$currents blocked but with minimum $\mathrm{Ca}^{2+}$ current rundown. As shown in Figure 5, the magnitude of $\mathrm{Ca}^{2+}$ tail currents (peak and integral) were strongly correlated with the bursting phenotype of subicular neurons; strong bursting neurons had the largest $\mathrm{Ca}^{2+}$ tail currents, weak bursting neurons had smaller, briefer $\mathrm{Ca}^{2+}$ tail currents, and regular spiking neurons had the smallest, briefest $\mathrm{Ca}^{2+}$ tail currents. Tail currents from CA1 pyramidal neurons, which show a regular-spiking firing pattern, were found to be comparable with regular-spiking subicular neurons. These results strongly support the hypothesis that a $\mathrm{Ca}^{2+}$ tail current elicited by a brief depolarization promotes bursting in subicular pyramidal neurons.

Additional nucleated-patch experiments were performed to study the activation, inactivation, and deactivation of $\mathrm{Ca}^{2+}$ currents mediating the tail. $\mathrm{Na}^{+}$currents were blocked with $0.5 \mu \mathrm{M}$ TTX in most of these experiments. The tail currents from bursting neurons steadily increased with larger command voltages from a holding potential of $-70 \mathrm{mV}$. Based on a fit with a single Boltzmann equation, tail currents began to activate near -40 $\mathrm{mV}$, with a half-activation voltage of $-13 \mathrm{mV}$, and slope factor of 12. The data were better fit, however, with sum of two Boltzmann functions, suggesting the existence of at least two components, corresponding to low-voltage-activated (LVA) $\left(V_{1 / 2}=-31 \mathrm{mV}\right.$; $k=6 \mathrm{mV})$ and high-voltage-activated (HVA) $\left(V_{1 / 2}=2 \mathrm{mV} ; k=\right.$ $5 \mathrm{mV}$ ) $\mathrm{Ca}^{2+}$ conductances (Fig. $6 A$ ).

$\mathrm{Ca}^{2+}$ current inactivation was examined using 50-100 msec prepulses to different membrane potentials before a test step to 20 $\mathrm{mV}$. During prepulses to $0 \mathrm{mV}$ (maximum inactivation), $58 \pm 3 \%$ of the peak currents inactivated with a time constant of $10 \pm 0.6$ msec (single exponential fit; $n=5$ ). The remaining current inactivated too slowly for kinetics to be determined from these experiments. Tail-current amplitudes after the brief test step were plotted against the prepulse potential. Inactivation steadily increased at more positive prepotentials but was never complete. A single Boltzmann fit of the data yielded a half-inactivation voltage of $-25 \mathrm{mV}$ and slope factor of $20 \mathrm{mV}$. A sum of two Boltzmann equations provided better fits of the data, suggesting the existence of at least two inactivating components (Fig. 6B).

An important feature of the $\mathrm{Ca}^{2+}$ tail current, with regard to bursting, is its deactivation time course. We fit the decay of tail currents with two exponentials. The fast component had a time constant of $0.05-0.16 \mathrm{msec}$ and accounted for $60-80 \%$ of the deactivation (depending on membrane potential; for fit details, see legend of Fig. 6). The slow decay time constant accounting for the remaining deactivation was $0.32 \mathrm{msec}$ at $-100 \mathrm{mV}$ but became slower at more depolarized potentials, up to $2.9 \mathrm{msec}$ at $-40 \mathrm{mV}$ (Fig. 6C). Because action potentials within a burst repolarize to between -40 and $-50 \mathrm{mV}$, the slower of these time constants is particularly relevant during burst firing.

In some neurons, such as invertebrate pacemaker and prefrontal cortical neurons, the afterdepolarization underlying rhythmic or burst firing has been reported to be mediated by $\mathrm{Ca}^{2+}$ activated, nonselective cation conductances (Adams and Levitan, 1985; Swandulla and Lux, 1985; Haj-Dahmane and Andrade, 1997). Considering the very positive reversal potential $(+102$ $\mathrm{mV}$ ) and the voltage-dependent deactivation (a property not related to internal $\mathrm{Ca}^{2+}$ levels) of the tail currents in subicular neurons, we infer that the tail current mediating subicular bursting is a $\mathrm{Ca}^{2+}$ conductance rather than a $\mathrm{Ca}^{2+}$ activated nonselective conductance. In support of this idea, when 10-20 mM BAPTA was included in the patch pipette, both bursting and the 
A strong bursting (SB) weak bursting (WB) regular spiking (RS)
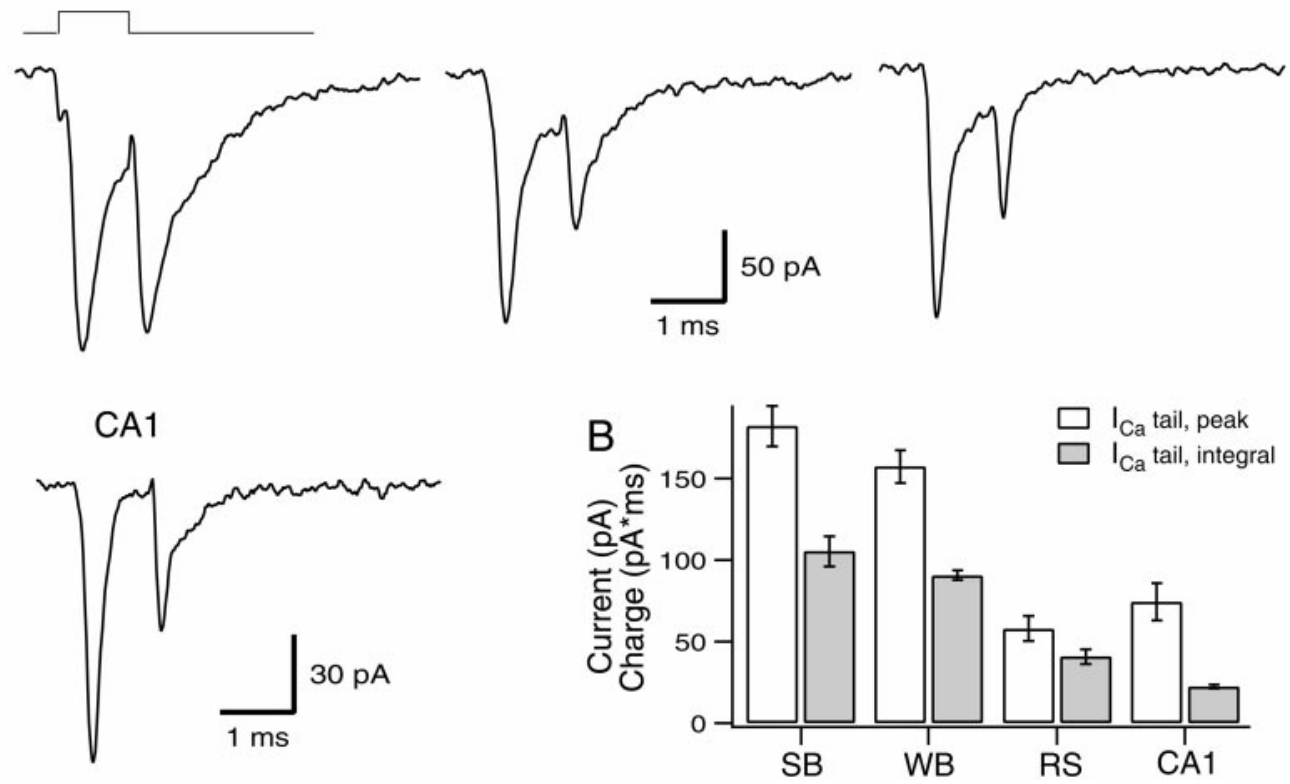

Figure 5. Correlation of $\mathrm{Ca}^{2+}$ tail currents with bursting. $A$, Examples of mixed inward currents $\left(\mathrm{Na}^{+}\right.$and $\left.\mathrm{Ca}^{2+}\right)$ from each type of neuron in response to 1 msec depolarizations from -70 to $20 \mathrm{mV}$. Note the decrease in $\mathrm{Ca}^{2+}$ tail currents from strong bursting to regular spiking subicular neurons. Patches having similar peak $\mathrm{Na}^{+}$currents during the step are illustrated to facilitate comparison. Currents from a CA1 pyramidal neuron are also shown. Data were obtained with a Cs-gluconate-based internal solution. $B$, Pooled data showing the decrease in both the peak and integral of $\mathrm{Ca}^{2+}$ tail currents from bursting to nonbursting neurons $(n=6$ for strong bursting subicular neurons; $n=5$ for all other cell types of neurons). Statistical analysis shows that there is a significant difference between nonbursting and bursting neurons in both the peak and integral of $\mathrm{Ca}^{2+}$ tail currents (one-way ANOVA; $p<0.05$; with Newman-Keuls test for multiple comparisons).
$\mathrm{Ca}^{2+}$ tail currents were similar to those observed with normal internal solution (data not shown).

In an effort to determine which $\mathrm{Ca}^{2+}$ channel subtype mediates the tail currents, we examined the action of several specific and nonspecific $\mathrm{Ca}^{2+}$ channel blockers on tail currents (Table 1). Only approximately one-third of the tail currents were blocked by the N/P/Q-type blocker $\omega$-conotoxin MVIIC, $12 \%$ were blocked by the L-type blocker nimodipine (neither of which blocked bursting in current-clamp experiments; data not shown), and $20 \%$ of the tail was blocked by $50-100 \mu \mathrm{M} \mathrm{Ni}{ }^{2+}$. Although it was surprising that $500 \mu \mathrm{M} \mathrm{Cd}^{2+}$ blocked only $60 \%$ of the tail currents, these pharmacological results clearly indicate that multiple types of $\mathrm{Ca}^{2+}$ channels underlie tail currents in subicular neurons.

Large, regenerative dendritic $\mathrm{Ca}^{2+}$ spikes are associated with bursting in many intrinsically bursting neurons (Wong and Prince, 1978; Golding et al., 1999; Helmchen et al., 1999). However, we found that subicular bursting neurons rarely generate $\mathrm{Ca}^{2+}$ spikes. Even under conditions in which CA3 and CA1 pyramidal neurons readily produce $\mathrm{Ca}^{2+}$ spikes (bath application of 0.5-1.0 $\mu \mathrm{M}$ TTX) (Wong and Prince, 1978; Golding et al., 1999), 6 of 10 subicular neurons did not generate $\mathrm{Ca}^{2+}$ spikes in response to large current injections up to $2 \mathrm{nA}$ (Fig. $7 A$ ). The remaining 4 of 10 bursting subicular neurons produced $\mathrm{Ca}^{2+}$ spikes in the presence of TTX, but those spikes required very large depolarizations (threshold of more than $-20 \mathrm{mV}$ ) and the amplitudes of the resulting spikes were $<20 \mathrm{mV}$. Ca ${ }^{2+}$ imaging from the soma or proximal dendrites of subicular neurons during depolarizations in TTX showed a high threshold for $\mathrm{Ca}^{2+}$ entry, and the half-activation voltage (with a single Boltzmann fit) (Fig. $7 B$ ) was comparable with that of $\mathrm{Ca}^{2+}$ currents measured in nucleated patches (Fig. $6 \mathrm{~A}$, solid curve). These findings suggest that $\mathrm{Ca}^{2+}$ spikes are not associated with bursting in subicular pyramidal neurons.

Together, our results suggest that bursting in subicular pyramidal neurons is driven by a large $\mathrm{Ca}^{2+}$ conductance, which is activated by an action potential and remains on long enough after the spike to produce an afterdepolarization that drives subse- quent action potentials in a burst. However, an important question still remains with this proposed mechanism: why do neither $\mathrm{Cd}^{2+}$ nor zero $\mathrm{Ca}^{2+}$ block bursting with long current steps? We propose that blockade of $\mathrm{Ca}^{2+}$ currents by nonspecific $\mathrm{Ca}^{2+}$ channel blockers indirectly inhibits $\mathrm{Ca}^{2+}$-activated $\mathrm{K}^{+}$channels, leading to impairment in action potential repolarization. When combined with continued current injection and the shifted voltage dependence of $\mathrm{Na}^{+}$currents in zero- $\mathrm{Ca}^{2+}$ solution (Frankenhaeuser and Hodgkin, 1957), this slow action potential repolarization triggers additional action potential firing, an abnormal form of bursting different from that occurring in the normal condition. This hypothesis is supported by the finding that charybdotoxin, a selective blocker of fast, high-threshold $\mathrm{Ca}^{2+}$-activated $\mathrm{K}^{+}$channels, increased bursting with a decrease in spike amplitude $(n=$ 3) (Fig. 8A), very similar to the effects of $\mathrm{Cd}^{2+}$ and zero $\mathrm{Ca}^{2+}$ (Fig. $1 C, D)$. We also suggest that the reason why a high concentration of $\mathrm{Ni}^{2+}$ is such an efficient blocker of subicular bursting is that high $\mathrm{Ni}^{2+}$ reduces $\mathrm{Na}^{+}$as well as $\mathrm{Ca}^{2+}$ currents (Fig. 3D). With this dual effect, a high concentration of $\mathrm{Ni}^{2+}$ acts like a combination of zero $\mathrm{Ca}^{2+}$ and low TTX (Fig. 4C) and thus blocks both the normal bursting and the abnormal bursting occurring when $\mathrm{Ca}^{2+}$ currents are abolished.

Based on this model of action potential bursting in subicular neurons, we inferred that it might be possible to block bursting by reducing the $\mathrm{Ca}^{2+}$ tail current without blocking it completely. We reasoned that if we could reduce the $\mathrm{Ca}^{2+}$-dependent depolarization just below threshold for triggering subsequent action potentials, the remaining $\mathrm{Ca}^{2+}$ influx may allow enough $\mathrm{Ca}^{2+}$ activated $\mathrm{K}^{+}$channel activity for normal action potential repolarization, and bursting could be blocked. Several different $\mathrm{Ca}^{2+}$ concentrations were tested for their effect on strong bursting subicular neurons. In three of five neurons, we found a reduced $\mathrm{Ca}^{2+}$ concentration $(0.5-1.0 \mathrm{~mm})$ that blocked bursting completely (Fig. $8 B$ ). Although we could not completely block bursting in the other two neurons, possibly as a result of the delicate balance between $\mathrm{Ca}^{2+}$ and $\mathrm{Ca}^{2+}$-activated $\mathrm{K}^{+}$channels, the number of action potentials in a burst was decreased in $0.5-1.0$ 

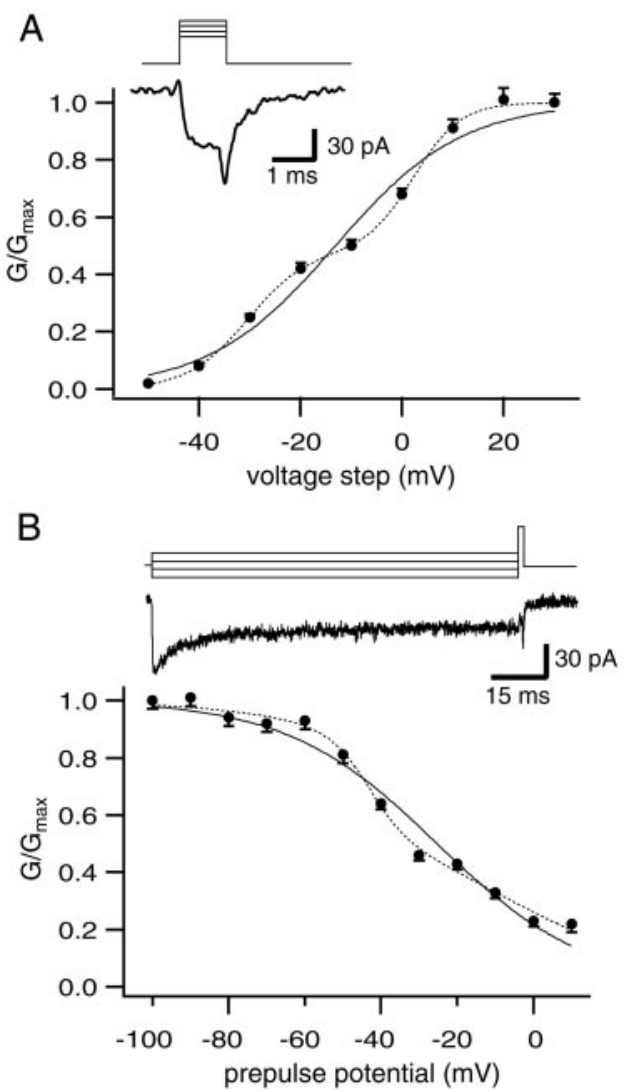

C

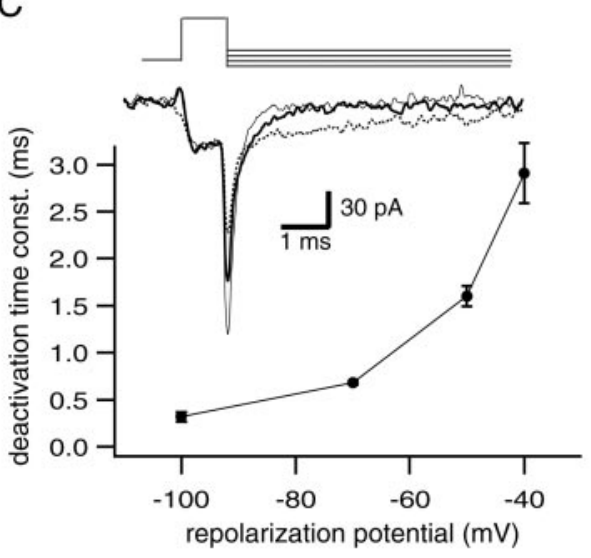

Figure 6. Biophysical properties of $\mathrm{Ca}^{2+}$ tail currents. A, Activation curve of $\mathrm{Ca}^{2+}$ tail currents constructed from 13 bursting subicular neurons. Peak tail currents at $-70 \mathrm{mV}$ are plotted as a function of command potential during the step depolarization (see diagram). A current trace below the diagram is an example response (average of 5 traces) to $0 \mathrm{mV}$ depolarization in a nucleated patch. Solid curve is the fit to a single Boltzmann function $G / G_{\max }=1 /\left(1+\exp \left(\left(V-V_{1 / 2}\right) /-k\right)\right)$ with a halfactivation voltage $\left(V_{1 / 2}\right)$ of $-13 \mathrm{mV}$ and slope factor $(k)$ of $12 \mathrm{mV}$. The dotted curve is a fit to the sum of two Boltzmann functions, with $\left(V_{1 / 2}\right)_{1}=$ $-30 \mathrm{mV}, k_{1}=6 \mathrm{mV}$ (amplitude, 0.48) and $\left(V_{1 / 2}\right)_{2}=2 \mathrm{mV}, k_{2}=5 \mathrm{mV}$ (amplitude, 0.52). B, Inactivation curve of $\mathrm{Ca}^{2+}$ tail currents constructed from 12 subicular neurons. Peak tail currents at $-70 \mathrm{mV}$ are plotted as a function of the prepotential during 50-100 msec prepulses before the 1 $\mathrm{msec}$ step depolarization to $+20 \mathrm{mV}$ (see diagram). A current trace below the diagram is an example response ( 2 traces were averaged) in a nucleated patch, showing both fast and slowly inactivating components during a $100 \mathrm{msec}$ prepulse to $0 \mathrm{mV}$. The solid curve is the fit of a Boltzmann function $G / G_{\max }=1 /\left(1+\exp \left(\left(V-V_{1 / 2}\right) / k\right)\right)$, with $\left(V_{1 / 2}\right)=-25 \mathrm{mV}, k=$ $20 \mathrm{mV}$. The dotted curve is the fit to a sum of two Boltzmann functions, with $\left(V_{1 / 2}\right)_{1}=-33 \mathrm{mV}, k_{1}=5 \mathrm{mV}$ (amplitude, 0.32$)$ and $\left(V_{1 / 2}\right)_{2}=-11$ $\mathrm{mV}, k_{2}=24 \mathrm{mV}$ (amplitude, 0.68). $C$, Deactivation time constants as a $\mathrm{mm} \mathrm{Ca}{ }^{2+}$ in these cells, supporting our proposed mechanism of bursting in subicular pyramidal neurons.

\section{DISCUSSION}

Considering the central role of subiculum in memory processing and the prominence of bursting as a means of signaling in these neurons, elucidating the mechanisms of bursting constitutes an important step toward understanding the cellular and molecular properties of neurons mediating memory formation in the hippocampus. We find that a $\mathrm{Ca}^{2+}$ tail current, mediated by multiple $\mathrm{Ca}^{2+}$ channel subtypes, is activated by an action potential, producing an afterdepolarization that drives burst firing in subicular neurons.

Although our data suggest that several $\mathrm{Ca}^{2+}$ channel subtypes may contribute to tail currents underlying an afterdepolarization, several arguments suggest that activation of $\mathrm{LVA} \mathrm{Ca}^{2+}$ channels alone is not sufficient to drive bursting in subicular neurons. First, no sign of a slow depolarization was observed at subthreshold membrane potentials (Fig. 4). Rather, an action potential was required to elicit the slow depolarization, suggesting the need for activation of $\mathrm{HVA} \mathrm{Ca}^{2+}$ channels. Second, subicular bursting was not prevented when cells were held at depolarized membrane potentials, in which $\mathrm{LVA} \mathrm{Ca}^{2+}$ channels are primarily inactivated (Staff et al., 2000). These observations are consistent with our finding that large depolarizations were required to activate half of the $\mathrm{Ca}^{2+}$ current or $\mathrm{Ca}^{2+}$ influx measured in imaging experiments ( -13 and $-21 \mathrm{mV}$ based on single Boltzmann fits). The need for recruitment of $\mathrm{HVA} \mathrm{Ca}^{2+}$ channels by an action potential distinguishes the burst mechanisms in subiculum from that of thalamic relay neurons and dorsal root ganglion neurons. In those neurons, activation of LVA, T-type $\mathrm{Ca}^{2+}$ channels produces a low-threshold $\mathrm{Ca}^{2+}$ spike, which drives the burst (White et al., 1989; McCormick and Bal, 1997; Destexhe et al., 1998).

A relatively small fraction of the $\mathrm{HVA} \mathrm{Ca}^{2+}$ current appears to be mediated by L-type current ( $\mathrm{Ca}_{\mathrm{v}} 1$ family), based on $12 \%$ block by nimodipine. A larger fraction appears to be mediated by N-, P-, $\mathrm{Q}$-, and R-type $\mathrm{Ca}^{2+}$ channels ( $\mathrm{Ca}_{\mathrm{v}} 2$ family). Thirty-one percent of the $\mathrm{Ca}^{2+}$ tail current was blocked by $\omega$-conotoxin MVIIC, which blocks the P/Q and $\mathrm{N}$ subtypes $\left(\mathrm{Ca}_{\mathrm{v}} 2.1\right.$ and $2.2 ; \alpha_{1 \mathrm{~A}}$ and $\left.\alpha_{1 \mathrm{~B}}\right)$. An additional component may be mediated by R-type channels $\left(\mathrm{Ca}_{\mathrm{v}} 2.3 ; \alpha_{1 \mathrm{E}}\right)$, which are resistant to nimodipine and MVIIC but are sensitive to $\mathrm{Ni}^{2+}$ (Tottene et al., 1996, 2000). The potential importance of R-type channels in mediating bursting is indicated by the inability of nimodipine and $\omega$-conotoxin MVIIC to block bursting (data not shown).

The fraction of current mediated by LVA, T-type channels is difficult to evaluate on the basis of pharmacology. Low concentrations of $\mathrm{Ni}^{2+}$ block only one of the three T-type channels

function of repolarization potential (top) constructed from seven bursting subicular neurons. Three current traces are shown below the diagram, demonstrating the voltage dependence of $\mathrm{Ca}^{2+}$ tail current deactivation. Each trace is an average of three to four responses from the same nucleated patch. Traces are shown for repolarization from +20 to -100 (thin), -70 (thick), and $-40 \mathrm{mV}$ (dashed) $\mathrm{mV}$. Averaged traces including these were fit to a two-exponential function, and the slower time constants are plotted as a function of the repolarization potential. The fast time constants (with the relative amplitude) are $0.05 \pm 0.02(0.76 \pm 0.16)$, $0.09 \pm 0.01(0.60 \pm 0.03), 0.16 \pm 0.03(0.77 \pm 0.01)$, and $0.14 \pm 0.02$ $(0.80 \pm 0.02) \mathrm{msec}$ for the repolarization potentials shown on the graph (left to right). Each cell in $A-C$ was patched twice, as described in Figure 4 , except for those used to construct the inactivation curve; nine patches having tail currents of $>80 \mathrm{pA}$ were included in that analysis. 


\begin{tabular}{|c|c|c|c|c|c|}
\hline & $\begin{array}{l}\omega \text {-Conotoxin MVIIC } \\
10 \mu \mathrm{M}\end{array}$ & $\begin{array}{l}\text { Nimodipine } \\
5 \mu \mathrm{M}\end{array}$ & $\begin{array}{l}\mathrm{Ni}^{2+} \\
50 \text { or } 100 \mu \mathrm{M}\end{array}$ & $\begin{array}{l}\mathrm{Ni}^{2+} \\
1 \mathrm{mM}\end{array}$ & $\begin{array}{l}\mathrm{Cd}^{2+} \\
250 \text { or } 500 \mu \mathrm{M}\end{array}$ \\
\hline $\begin{array}{l}\% \text { block of tail currents } \\
\text { by each drug }\end{array}$ & $\begin{aligned} 31 & \pm 1 \\
n & =5\end{aligned}$ & $\begin{aligned} 12 & \pm 3 \\
n & =5\end{aligned}$ & $\begin{aligned} 20 & \pm 3 \\
n & =7\end{aligned}$ & $\begin{aligned} 79 & \pm 2 \\
n & =4\end{aligned}$ & $\begin{aligned} 59 & \pm 3 \\
n & =4\end{aligned}$ \\
\hline
\end{tabular}

$\left(\mathrm{Ca}_{\mathrm{v}} 3.2 ; \alpha_{1 \mathrm{H}}\right)$ but also block some R-type channels (high- or intermediate-voltage-activated) and some L-type, HVA channels (Lee et al., 1999b; Soong et al., 1993; Williams et al., 1994; Tottene et al., 1996, 2000; Zamponi et al., 1996). Almost half of the activation curve, when fit with two Boltzmann functions, could be accounted for by a low half-activation voltage $(-31 \mathrm{mV})$. Although this suggests that as much as half of the current contributing to the tail may be from LVA, T-type $\mathrm{Ca}^{2+}$ channels ( $\mathrm{Ca}_{\mathrm{v}} 3$ family), some of this fraction may be attributable to intermediate-voltage-activated, R-type $\mathrm{Ca}^{2+}$ channels (Soong et al., 1993; Tottene et al., 1996; Magistretti et al., 2000). Consistent with a larger contribution from R-type, rather than T-type, channels are the rapid activation of the current and rapid, voltagedependent deactivation kinetics (Randall and Tsien, 1997; Lee et al., 1999a). Because of the inherent difficulty correlating native $\mathrm{Ca}^{2+}$ channel properties to specific channels expressed in heterologous systems, better dissection of the $\mathrm{Ca}^{2+}$ channel subtypes underlying subicular bursting is likely to require more specific toxins and/or molecular approaches.

Bursting in subicular pyramidal neurons requires the activation of an HVA $\mathrm{Ca}^{2+}$ current but not a $\mathrm{Ca}^{2+}$ spike (Stewart and Wong, 1993; Taube, 1993; Mattia et al., 1997). This distinguishes bursting in the subiculum from that in neighboring CA1 pyramidal neurons, in which action potential bursts can be triggered by dendritic $\mathrm{Ca}^{2+}$ spikes in response to strong synaptic activation or dendritic current injection (Golding et al., 1999). Dendritic $\mathrm{Ca}^{2+}$ spikes can also trigger bursting in neocortical pyramidal neurons (Helmchen et al., 1999; Larkum et al., 1999; Williams and Stuart, 1999).

Persistent $\mathrm{Na}^{+}$current has also been suggested to contribute to bursting in some neocortical neurons and CA1 pyramidal neurons (Wong and Prince, 1978; Alonso and Llinas, 1989; Silva et al., 1991; Azouz et al., 1996; Jensen et al., 1996; Golding and Spruston, 1998; Mantegazza et al., 1998; Brumberg et al., 2000). Although we cannot rule out the possibility that $\mathrm{Na}^{+}$currents contribute partially to the slow depolarization underlying bursting in subicular neurons, either from persistent $\mathrm{Na}^{+}$current or return current from the dendrites because of backpropagating action potentials, this contribution appears to be minor compared with that of the $\mathrm{Ca}^{2+}$ tail current.

It is possible that $\mathrm{Ca}^{2+}$ tail currents similar to those described here mediate bursting in other cell types, although the responsible currents have not been studied in detail. Afterdepolarizationmediated burst firing has been described in several bursting neurons, including spinal motor neurons and invertebrate neurons (Kandel and Spencer, 1961; Calvin and Schwindt, 1972; Thompson and Smith, 1976; Wong and Prince, 1981). Hippocampal CA3 pyramidal neurons also exhibit burst firing as a result of a $\mathrm{Ca}^{2+}$-dependent afterdepolarization, although this may be triggered, at least in part, by dendritic $\mathrm{Ca}^{2+}$ spikes (Wong and Prince, 1978, 1981; Traub et al., 1994).

Bursting in subicular pyramidal neurons depends on a delicate balance between inward $\mathrm{Na}^{+}$and $\mathrm{Ca}^{2+}$ currents and outward
$\mathrm{K}^{+}$currents. An $\mathrm{Na}^{+}$action potential is required to activate a $\mathrm{Ca}^{2+}$ conductance, which produces an afterdepolarization driving subsequent $\mathrm{Na}^{+}$action potentials. The $\mathrm{Ca}^{2+}$ currents also lead to activation of $\mathrm{Ca}^{2+}$-activated $\mathrm{K}^{+}$currents, which contribute to burst termination. Muscarinic $\mathrm{K}^{+}$currents have also been
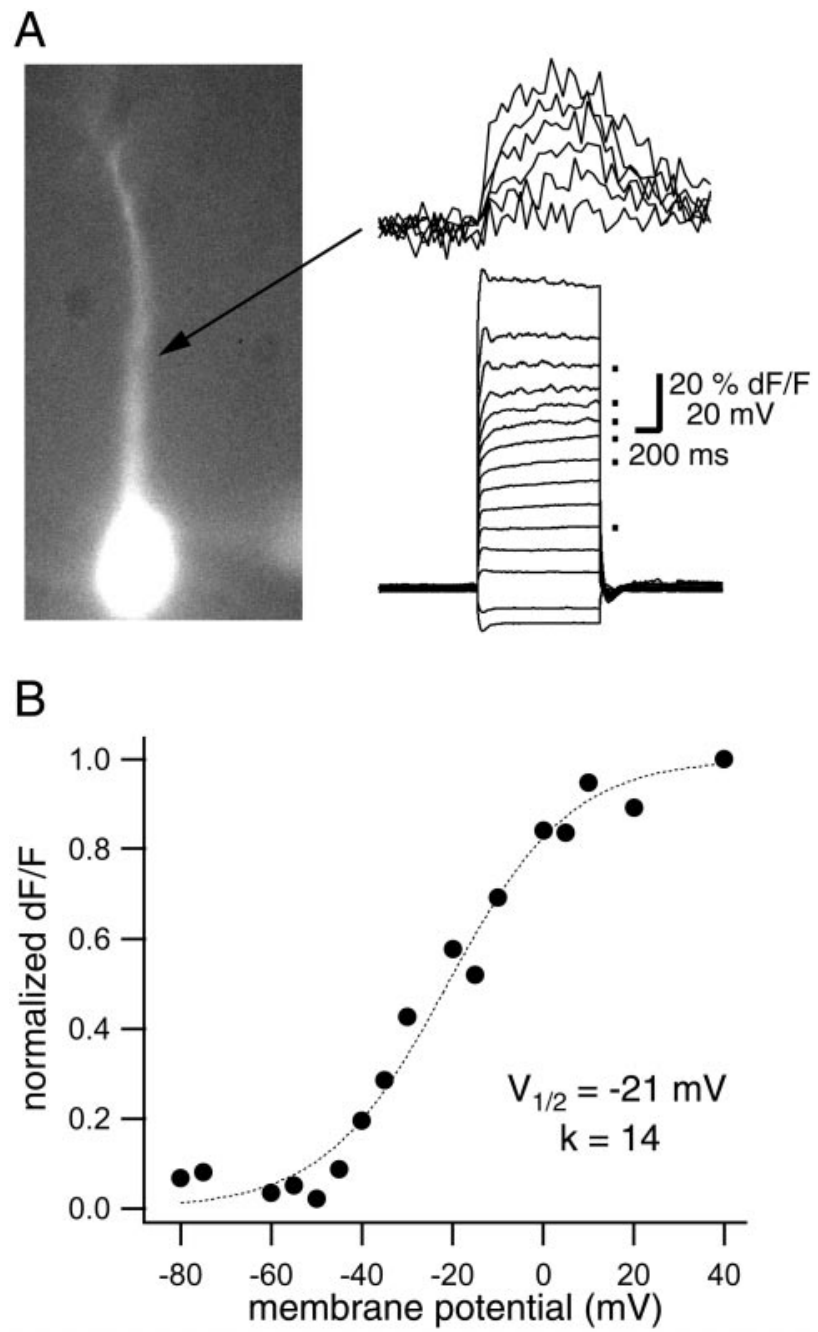

Figure 7. $\mathrm{Ca}^{2+}$ imaging in subicular bursting neurons. $A, \mathrm{Ca}^{2+}$ imaging from the proximal apical dendrite ( $30 \mu \mathrm{m}$ from the center of the soma) in a fura-2-filled subicular pyramidal neuron. Large depolarizations in the presence of $0.5 \mu \mathrm{M}$ TTX failed to elicit $\mathrm{Ca}^{2+}$ spikes (somatic current-clamp recording with $1 \mathrm{sec}$ current injections of $-200,-100,100-1000,1200$, 1400 , and $1800 \mathrm{pA})$. As indicated by the $\mathrm{d} F / F$ responses above the voltage responses, depolarization produced considerable $\mathrm{Ca}^{2+}$ entry $(300,600-$ 900 , and $1200 \mathrm{pA}$ responses shown, indicated by a small dot next to the voltage responses). $B$, A plot of normalized $\mathrm{d} F / F$ versus membrane potential at the end of the current step yields an activation curve for $\mathrm{Ca}^{2+}$ entry. The data are compiled from three neurons, with imaging from the soma in two cases and the proximal dendrite in one case. The dotted curve is a fit with a Boltzmann function, with $V_{1 / 2}=-21 \mathrm{mV}$ and $k=14 \mathrm{mV}$. 
A

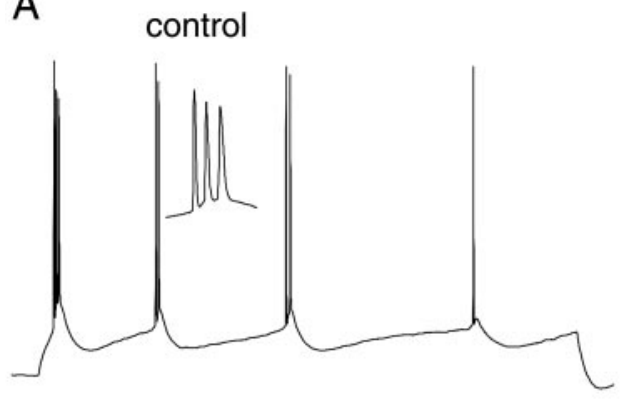

Figure 8. Subicular bursting is the result of a balance between $\mathrm{Na}^{+}, \mathrm{Ca}^{2+}$, and $\mathrm{K}^{+}$ currents. $A$, The $\mathrm{Ca}^{2+}$-activated $\mathrm{K}^{+}$channel blocker charybdotoxin increases bursting. Note that the effect is similar to that of zero $\mathrm{Ca}^{2+}$ or $\mathrm{Cd}^{2+}$ (see Fig. $1 C, D$ ). B, Reduction of external $\mathrm{Ca}^{2+}$ concentration blocks bursting, demonstrating the delicate balance of inward and outward currents affecting bursting. Calibration bars in $B$ also apply to $A$. The range of current injection is 123-190 pA.

\section{$B$}

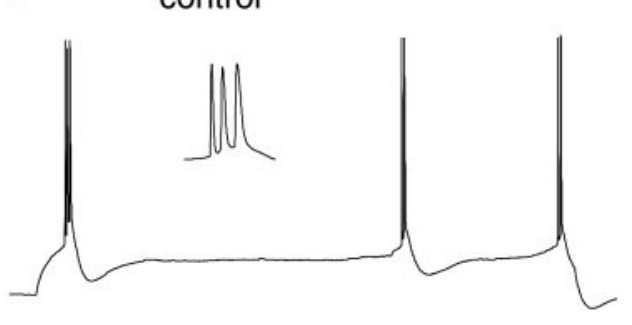
$100 \mathrm{nM}$ charybdotoxin
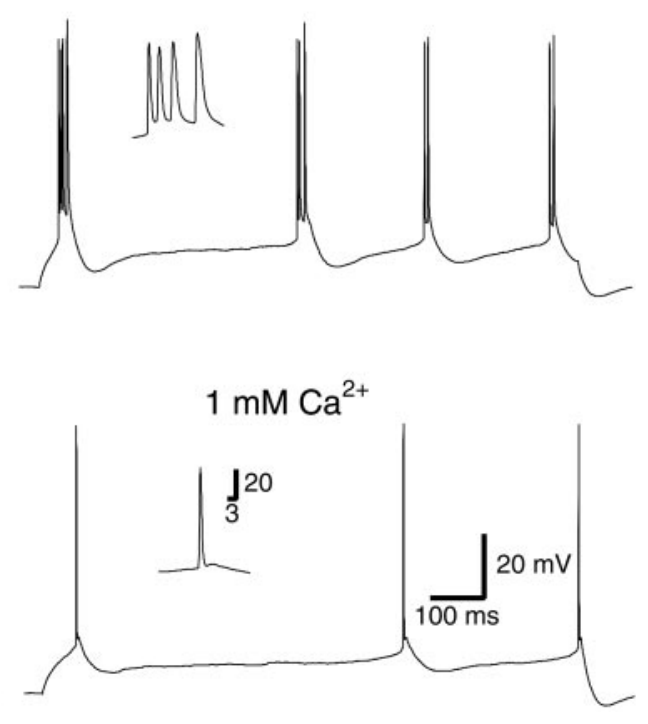

shown to curtail bursting of subicular neurons (Kawasaki et al., 1999). $\mathrm{Na}^{+}$channel inactivation may also contribute to burst termination, because the increasing voltage threshold for successive action potential initiation during the burst, as seen in our data (Fig. 4), may reflect incomplete recovery of $\mathrm{Na}^{+}$channels from inactivation during high-frequency burst firing.

This balance of inward and outward currents provides an explanation for our previous result showing that application of a low concentration of 4-AP, which blocks D-type potassium currents, transforms regular spiking neurons into a burst-firing mode (Staff et al., 2000). Because a quantitative rather than qualitative difference in the $\mathrm{Ca}^{2+}$ tail currents appears to determine the firing phenotype of subicular and CA1 neurons, manipulations that alter the balance of inward and outward conductances can lead to changes in the firing output mode of these neurons.

The intricate interactions between $\mathrm{Na}^{+}, \mathrm{Ca}^{2+}$, and $\mathrm{Ca}^{2+}$ activated $\mathrm{K}^{+}$currents also complicate pharmacological analysis of bursting in subicular neurons. Mattia et al. (1997) concluded that an $\mathrm{Na}^{+}$conductance mediates subicular bursting based on the finding that the depolarizing envelope underlying a burst is blocked by TTX. Our data suggest, however, that the slow depolarization underlying bursting depends only indirectly on $\mathrm{Na}^{+}$ channels. Complete block of $\mathrm{Na}^{+}$channels would eliminate the slow afterdepolarization by preventing the action potentials necessary to trigger it; partial block of $\mathrm{Na}^{+}$channels does not prevent action potential firing but suppresses bursting by raising action potential threshold beyond the level achieved during the afterdepolarization. The balance of currents underlying bursting also means that blockade of $\mathrm{Ca}^{2+}$ channels alone can actually increase bursting (during long current injections) as a result of the accompanying decrease in $\mathrm{Ca}^{2+}$-activated $\mathrm{K}^{+}$channel activation. Millimolar $\mathrm{Ni}^{2+}$ blocks bursting effectively in subicular neurons because of its multiple effects: near complete block of $\mathrm{Ca}^{2+}$ currents and partial block of fast $\mathrm{Na}^{+}$currents.

These findings have implications for the treatment of epilepsy using medicines that affect voltage-gated $\mathrm{Na}^{+}$and $\mathrm{Ca}^{2+}$ channels (Stefani et al., 1997; Ragsdale and Avoli, 1998). Drugs targeting $\mathrm{Ca}^{2+}$ channels may lead to undesirable hyperexcitability in the subiculum, a brain region susceptible to seizures (Walther et al.,
1986; Behr and Heinemann, 1996; Funahashi et al., 1999). A more effective strategy for controlling seizures might be partial block of $\mathrm{Ca}^{2+}$ channels or block of a combination of $\mathrm{Na}^{+}$and $\mathrm{Ca}^{2+}$ channels. Our findings also underscore the notion that alterations of several different channel types may lead to abnormal bursting and epileptic discharge, a fact consistent with multiple causes of this family of disorders (McNamara, 1994).

Subiculum serves as a relay center between the hippocampal complex and numerous cortical and subcortical structures. Subicular neurons receive synaptic input from entorhinal cortex and CA1 pyramidal cells and not only project back to the deep layer cells in entorhinal cortex but also project to several areas involved in various aspects of memory, such as prefrontal cortex and nucleus accumbens (Lopes da Silva et al., 1990; O'Mara et al., 2001). Subicular neurons therefore appear to be in an ideal position to integrate and distribute information from hippocampus to many brain regions. The predominance of action potential bursting in these neurons suggests that this firing mode is an important means by which information is distributed to these networks. Thus, the $\mathrm{Ca}^{2+}$ tail current driving bursting may be central to the ability of the hippocampus to coordinate memory processes across multiple brain regions.

\section{REFERENCES}

Adams WB, Levitan IB (1985) Voltage and ion dependences of the slow currents which mediate bursting in Aplysia neurone R15. J Physiol (Lond) 360:69-93.

Alger BE, Nicoll RA (1980) Epileptiform burst afterhyperpolarization: calcium-dependent potassium potential in hippocampal CA1 pyramidal cells. Science 210:1122-1124.

Alonso A, Llinas RR (1989) Subthreshold $\mathrm{Na}^{+}$-dependent theta-like rhythmicity in stellate cells of entorhinal cortex layer II. Nature 342:175-177.

Azouz R, Jensen MS, Yaari Y (1996) Ionic basis of spike afterdepolarization and burst generation in adult rat hippocampal CA1 pyramidal cells. J Physiol (Lond) 492:211-223.

Behr J, Heinemann U (1996) Low $\mathrm{Mg}^{2+}$ induced epileptiform activity in the subiculum before and after disconnection from rat hippocampal and entorhinal cortex slices. Neurosci Lett 205:25-28.

Brumberg JC, Nowak LG, McCormick DA (2000) Ionic mechanisms underlying repetitive high-frequency burst firing in supragranular cortical neurons. J Neurosci 20:4829-4843.

Calvin WH, Schwindt PC (1972) Steps in production of motoneuron spikes during rhythmic firing. J Neurophysiol 35:297-310. 
Davies DC, Wilmott AC, Mann DM (1988) Senile plaques are concentrated in the subicular region of the hippocampal formation in Alzheimer's disease. Neurosci Lett 94:228-233.

Deschenes M, Roy JP, Steriade M (1982) Thalamic bursting mechanism: an inward slow current revealed by membrane hyperpolarization. Brain Res 239:289-293.

Destexhe A, Neubig M, Ulrich D, Huguenard J (1998) Dendritic lowthreshold calcium currents in thalamic relay cells. J Neurosci 18:3574-3588.

Fox AP, Nowycky MC, Tsien RW (1987) Kinetic and pharmacological properties distinguishing three types of calcium currents in chick sensory neurones. J Physiol (Lond) 394:149-172.

Frankenhaeuser B, Hodgkin AL (1957) The action of calcium of the electrical properties of squid axons. J Physiol (Lond) 137:218-244.

Funahashi M, Harris E, Stewart M (1999) Re-entrant activity in a presubiculum-subiculum circuit generates epileptiform activity in vitro. Brain Res 849:139-146.

Gabrieli JDE, Brewer JB, Desmond JE, Glover GH (1997) Separate neural bases of two fundamental memory processes in the human medial temporal lobe. Science 276:264-266.

Golding NL, Spruston N (1998) Dendritic sodium spikes are variable triggers of axonal action potentials in hippocampal CA1 pyramidal neurons. Neuron 21:1189-1200.

Golding NL, Jung HY, Mickus T, Spruston N (1999) Dendritic calcium spike initiation and repolarization are controlled by distinct potassium channel subtypes in CA1 pyramidal neurons. J Neurosci 19:8789-8798.

Haj-Dahmane S, Andrade R (1997) Calcium-activated cation nonselective current contributes to the fast afterdepolarization in rat prefrontal cortex neurons. J Neurophysiol 78:1983-1989.

Helmchen F, Svoboda K, Denk W, Tank DW (1999) In vivo dendritic calcium dynamics in deep-layer cortical pyramidal neurons. Nat Neurosci 2:989-996.

Hyman BT, Van Horsen GW, Damasio AR, Barnes CL (1984) Alzheimer's disease: cell-specific pathology isolates the hippocampal formation. Science 225:1168-1170.

Jahnsen H, Llinas R (1984) Ionic basis for the electro-responsiveness and oscillatory properties of guinea-pig thalamic neurones in vitro. J Physiol (Lond) 349:227-247.

Jarrard LE (1986) Selective hippocampal lesions and behavior: implications for current research and theorizing. In: The hippocampus (Issacson RL, Pribam KH, eds), pp 93-126. New York: Plenum.

Jensen MS, Azouz R, Yaari Y (1996) Spike after-depolarization and burst generation in adult rat hippocampal CA1 pyramidal cells. J Physiol (Lond) 492:199-210.

Kandel ER, Spencer WA (1961) Electrophysiology of hippocampal neurons. II. After potentials and repetitive firing. J Neurophysiol 24:243-259.

Kawasaki H, Palmieri C, Avoli M (1999) Muscarinic receptor activation induces depolarizing plateau potentials in bursting neurons of the rat subiculum. J Neurophysiol 82:2590-2601.

Larkum ME, Zhu JJ, Sakmann B (1999) A new cellular mechanism for coupling inputs arriving at different cortical layers. Nature 398:338-341.

Lee JH, Daud AN, Cribbs LL, Lacerda AE, Pereverzev A, Klockner U, Schneider T, Perez-Reyes E (1999a) Cloning and expression of a novel member of the low voltage-activated T-type calcium channel family. J Neurosci 19:1912-1921.

Lee JH, Gomora JC, Cribbs LL, Perez-Reyes E (1999b) Nickel block of three cloned T-type calcium channels: low concentrations selectively block alpha1H. Biophys J 77:3034-3042.

Lisman JE (1997) Bursts as a unit of neural information: making unreliable synapses reliable. Trends Neurosci 20:38-43.

Lopes da Silva FH, Witter MP, Boeijinga PH, Lohman AH (1990) Anatomic organization and physiology of the limbic cortex. Physiol Rev 70:453-511

Magistretti J, Brevi S, de Curtis M (2000) A blocker-resistant, fastdecaying, intermediate-threshold calcium current in palaeocortical pyramidal neurons. Eur J Neurosci 12:2376-2386.

Mantegazza M, Franceschetti S, Avanzini G (1998) Anemone toxin (ATX II)-induced increase in persistent sodium current: effects on the firing properties of rat neocortical pyramidal neurones. J Physiol (Lond) 507:105-116.

Mattia D, Hwa GG, Avoli M (1993) Membrane properties of rat subicular neurons in vitro. J Neurophysiol 70:1244-1248.

Mattia D, Kawasaki H, Avoli M (1997) In vitro electrophysiology of rat subicular bursting neurons. Hippocampus 7:48-57.

McCormick DA, Bal T (1997) Sleep and arousal: thalamocortical mechanisms. Annu Rev Neurosci 20:185-215.

McNamara JO (1994) Cellular and molecular basis of epilepsy. J Neurosci 14:3413-3425.
Miles R, Wong RK (1986) Excitatory synaptic interactions between CA3 neurones in the guinea-pig hippocampus. J Physiol (Lond) 373:397-418

Naber PA, Witter MP (1998) Subicular efferents are organized mostly as parallel projections: a double-labeling, retrograde-tracing study in the rat. J Comp Neurol 393:284-297.

O'Mara SM, Commins S, Anderson M, Gigg J (2001) The subiculum: a review of form, physiology and function. Prog Neurobiol 64:129-155.

Paulsen O, Sejnowski TJ (2000) Natural patterns of activity and longterm synaptic plasticity. Curr Opin Neurobiol 10:172-179.

Ragsdale DS, Avoli M (1998) Sodium channels as molecular targets for antiepileptic drugs. Brain Res Brain Res Rev 26:16-28.

Randall AD, Tsien RW (1997) Contrasting biophysical and pharmacological properties of T-type and R-type calcium channels. Neuropharmacology 36:879-893.

Silva LR, Amitai Y, Connors BW (1991) Intrinsic oscillations of neocortex generated by layer 5 pyramidal neurons. Science 251:432-435.

Snider RK, Kabara JF, Roig BR, Bonds AB (1998) Burst firing and modulation of functional connectivity in cat striate cortex. J Neurophysiol 80:730-744.

Soong TW, Stea A, Hodson CD, Dubel SJ, Vincent SR, Snutch TP (1993) Structure and functional expression of a member of the low voltage-activated calcium channel family. Science 260:1133-1136.

Staff NP, Jung H, Thiagarajan T, Yao M, Spruston N (2000) Resting and active properties of pyramidal neurons in subiculum and CA1 of rat hippocampus. J Neurophysiol 84:2398-2408.

Stefani A, Spadoni F, Bernardi G (1997) Voltage-activated calcium channels: targets of antiepileptic drug therapy? Epilepsia 38:959-965.

Stewart M, Wong RK (1993) Intrinsic properties and evoked responses of guinea pig subicular neurons in vitro. J Neurophysiol 70:232-245.

Stuart G, Spruston N, Sakmann B, Häusser M (1997) Action potential initiation and backpropagation in neurons of the mammalian central nervous system. Trends Neurosci 20:125-131.

Swandulla D, Lux HD (1985) Activation of a nonspecific cation conductance by intracellular $\mathrm{Ca}^{2+}$ elevation in bursting pacemaker neurons of Helix pomatia. J Neurophysiol 54:1430-1443.

Taube JS (1993) Electrophysiological properties of neurons in the rat subiculum in vitro. Exp Brain Res 96:304-318.

Thompson SH, Smith SJ (1976) Depolarizing afterpotentials and burst production in molluscan pacemaker neurons. J Neurophysiol 39:153-161.

Tottene A, Moretti A, Pietrobon D (1996) Functional diversity of P-type and R-type calcium channels in rat cerebellar neurons. J Neurosci 16:6353-6363.

Tottene A, Volsen S, Pietrobon D (2000) $\alpha_{1 \mathrm{E}}$ subunits form the pore of three cerebellar R-type calcium channels with different pharmacological and permeation properties. J Neurosci 20:171-178.

Traub RD, Wong RK (1982) Cellular mechanism of neuronal synchronization in epilepsy. Science 216:745-747.

Traub RD, Jefferys JG, Miles R, Whittington MA, Toth K (1994) A branching dendritic model of a rodent CA3 pyramidal neurone. J Physiol (Lond) 481:79-95.

Van Hoesen GW (1982) The parahippocampal gyrus: new observation regarding its cortical connections in the monkey. Trends Neurosci $5: 345-350$.

Walther H, Lambert JD, Jones RS, Heinemann U, Hamon B (1986) Epileptiform activity in combined slices of the hippocampus, subiculum and entorhinal cortex during perfusion with low magnesium medium. Neurosci Lett 69:156-161.

White G, Lovinger DM, Weight FF (1989) Transient low-threshold $\mathrm{Ca}^{2+}$ current triggers burst firing through an afterdepolarizing potential in an adult mammalian neuron. Proc Natl Acad Sci USA 86:6802-6806.

Williams ME, Marubio LM, Deal CR, Hans M, Brust PF, Philipson LH, Miller RJ, Johnson EC, Harpold MM, Ellis SB (1994) Structure and functional characterization of neuronal alpha $1 \mathrm{E}$ calcium channel subtypes. J Biol Chem 269:22347-22357.

Williams SR, Stuart GJ (1999) Mechanisms and consequences of action potential burst firing in rat neocortical pyramidal neurons. J Physiol (Lond) 521:467-482.

Wong RK, Prince DA (1978) Participation of calcium spikes during intrinsic burst firing in hippocampal neurons. Brain Res 159:385-390.

Wong RK, Prince DA (1979) Dendritic mechanisms underlying penicillin-induced epileptiform activity. Science 204:1228-1231.

Wong RK, Prince DA (1981) Afterpotential generation in hippocampal pyramidal cells. J Neurophysiol 45:86-97.

Zamponi GW, Bourinet E, Snutch TP (1996) Nickel block of a family of neuronal calcium channels: subtype- and subunit-dependent action at multiple sites. J Membr Biol 151:77-90. 